\title{
Article
}

\section{Sex Differences in Lipid Profile across the Life Span in Patients with Type 2 Diabetes: A Primary Care-Based Study}

\author{
Martina Ambrož ${ }^{1, *(\mathbb{D})}$, Sieta T. de Vries ${ }^{1}\left(\mathbb{D}\right.$, Priya $\operatorname{Vart}^{1}{ }^{1}$, Robin P. F. Dullaart ${ }^{2}{ }^{(\mathbb{D}}$, Jeanine Roeters van Lennep ${ }^{3} \mathbb{C}$, \\ Petra Denig ${ }^{1 \oplus}$ and Klaas Hoogenberg ${ }^{4}$ \\ 1 Department of Clinical Pharmacy and Pharmacology, University of Groningen, \\ University Medical Center Groningen, 9700RB Groningen, The Netherlands; s.t.de.vries@umcg.nl (S.T.d.V.); \\ p.vart@umcg.nl (P.V.); p.denig@umcg.nl (P.D.) \\ 2 Department of Internal Medicine-Endocrinology, University of Groningen, \\ University Medical Center Groningen, 9700RB Groningen, The Netherlands; r.p.f.dullaart@umcg.nl \\ 3 Department of Internal Medicine, Erasmus Medical Center, University Medical Center Rotterdam, \\ 3015GD Rotterdam, The Netherlands; j.roetersvanlennep@erasmusmc.nl \\ 4 Department of Internal Medicine, Martini Hospital, 9728NT Groningen, The Netherlands; hoogenk@mzh.nl \\ * Correspondence: m.ambroz@umcg.nl
}

Citation: Ambrož, M.; de Vries, S.T.; Vart, P.; Dullaart, R.P.F.; Roeters van Lennep, J.; Denig, P.; Hoogenberg, K. Sex Differences in Lipid Profile across the Life Span in Patients with Type 2 Diabetes: A Primary Care-Based Study. J. Clin. Med. 2021, 10, 1775. https://doi.org/10.3390/jcm10081775

Academic Editor: Kei Nakajima

Received: 17 March 2021

Accepted: 16 April 2021

Published: 19 April 2021

Publisher's Note: MDPI stays neutral with regard to jurisdictional claims in published maps and institutional affiliations.

Copyright: (c) 2021 by the authors. Licensee MDPI, Basel, Switzerland. This article is an open access article distributed under the terms and conditions of the Creative Commons Attribution (CC BY) license (https:/ / creativecommons.org/licenses/by/ $4.0 /)$.

\begin{abstract}
We assessed sex differences across the life span in the lipid profile of type 2 diabetes (T2D) patients treated and not treated with statins. We used the Groningen Initiative to ANalyze Type 2 diabetes Treatment database, which includes T2D patients from the north of the Netherlands. Patients with a full lipid profile determined between 2010 and 2012 were included. We excluded patients treated with other lipid-lowering drugs than statins. Sex differences in low- and high-density lipoprotein cholesterol (LDL-c and HDL-c) and triglyceride (TG) levels across 11 age groups stratified by statin treatment were assessed using linear regression. We included 26,849 patients ( $51 \%$ women, $55 \%$ treated with statins). Without statins, women had significantly lower LDL-c levels than men before the age of 45 years, similar levels between 45 and 49 years, and higher levels thereafter. With statins, similar LDL-c levels were shown up to the age of 55, and higher levels in women thereafter. Women had significantly higher HDL-c levels than men, regardless of age or statin treatment. Men had significantly higher TG levels up to the age of 55 and 60, depending on whether they did not take or took statins, respectively, and similar levels thereafter. When managing cardiovascular risk in patients with T2D, attention is needed for the menopausal status of women and for TG levels in younger men.
\end{abstract}

Keywords: sex differences; age-related; life span; lipids; cholesterol; diabetes mellitus; type 2; statins; primary care

\section{Introduction}

Cardiovascular disease (CVD) is the leading cause of mortality in the world [1], and a person's lipid profile is an important aspect of the cardiovascular risk. It has been shown that men have a higher risk of atherosclerotic CVD than women [2] and that men develop CVD on average seven to ten years earlier than women [3]. Women are assumed to have more cardiometabolic reserves associated with female sex hormones, which gives them a biologic advantage when it comes to cardiovascular risk [4-6]. At younger ages, women have a more favorable lipid profile, characterized by lower levels of low-density lipoprotein cholesterol (LDL-c) and higher levels of high-density lipoprotein cholesterol (HDL-c) than men [7]. During the menopausal transition, women develop a more adverse lipid profile, characterized by an increase in LDL-c and a decrease in HDL-c [8-11].

In patients with type 2 diabetes (T2D), the risk of CVD is at least doubled in comparison to patients without diabetes [12,13]. Although T2D is a risk factor for both men and women, the impact of T2D on cardiovascular risk is markedly higher in women. Recent 
meta-analyses showed that T2D poses a $44 \%$ greater excess risk for coronary heart disease and a $27 \%$ greater excess risk for stroke in women compared to men $[14,15]$. Sex differences in the lipid profile are likely to play a role in this, since women with T2D have higher LDL-c and HDL-c levels and lower triglyceride (TG) levels than men with T2D [16]. It is not clear, however, whether such differences are present across all age groups and if they are influenced by menopausal status. This is likely, since a more atherogenic lipid and pro-inflammatory profile has been shown in postmenopausal diabetic women when compared to premenopausal non-diabetic or diabetic women [17].

To reduce cardiovascular risk in patients with $\mathrm{T} 2 \mathrm{D}$, a lipid-lowering treatment with a statin has been recommended for most of these patients, without differentiating between men and women [18,19]. The Cholesterol Treatment Trialists' Collaborators have shown that the proportional reduction in major vascular events per $\mathrm{mmol} / \mathrm{L}$ of LDL-c reduction with statins is similar between men and women with T2D [20]. Since T2D increases the risk of CVD in women more than in men, women should be treated at least as stringently as men [6]. Nonetheless, it seems that women with T2D are treated less aggressively with statins [21-23] and achieve cholesterol treatment targets less often than men [16,21,22,24-27].

Taken together, the above highlighted findings suggest that not only the presence of T2D but also menopausal status is relevant for the observed sex differences in cardiovascular risk. So far, a comprehensive analysis of sex differences in the lipid profile across the life span in patients with T2D is lacking. Furthermore, it is not clear to what extent possible sex differences across age groups can be mitigated by treatment with statins. Therefore, the aim of this study was to assess differences in the lipid profile between men and women with T2D across the life span and to assess to what extent are such differences influenced by treatment with statins. This information can provide insight into potentially undertreated populations and help guide personalized treatment.

\section{Materials and Methods}

\subsection{Study Design and Population}

We conducted a cross-sectional cohort study using data from the Groningen Initiative to ANalyse Type-2 diabetes Treatment (see GIANTT at https:/ / umcgresearch.org/facilities, accessed on 7 April 2021) database. This database contains anonymous primary care electronic medical record data from patients with T2D in the northern part of the Netherlands, including outcomes of diagnostic measurements and medication prescriptions. This population mostly consists of Caucasian people. The GIANTT data have been used for numerous studies $[23,28,29]$, including a study in which GIANTT was the reference careas-usual cohort [30]. Data imports are checked for completeness, and measurement units, coding of medication, and diagnostic measurements are harmonized before being imported in GIANTT.

Patients were included if they were treated by a general practitioner, had at least one full lipid profile (i.e., total cholesterol (TC), LDL-c, HDL-c, and TG) measurement between 1 January 2010 and 31 December 2012, had information about medical history of at least 180 days before the date of the lipid profile measurement, and were aged 18 years or older. We excluded patients without a known date of T2D diagnosis and those treated with other lipid-lowering drugs than statins (i.e., fibrates, bile acid sequestrants, nicotinic acid and derivatives, other lipid-modifying agents, or statins in a combination with other lipid-lowering drugs). The first date of the full lipid profile measurement was defined as the index date.

We obtained an exemption letter from the University Medical Center Groningen Medical Ethics Review Board (reference number M20.257509) indicating that an approval from the ethics committee was not needed for this study using anonymous data in the Netherlands. 


\subsection{Outcome Variables}

Our primary outcomes were the LDL-c, HDL-c, and TG levels in mmol/L at the index date. The secondary outcomes were the levels of TC and non-HDL cholesterol (non-HDL-c) at the index date.

Total cholesterol, LDL-c, HDL-c, and TG levels were assessed directly with standard enzymatic colorimetric methods (Roche elecsys C Module; Roche diagnostics, Switzerland) after an overnight fast. Non-HDL-c was calculated by subtracting HDL-c from TC.

\subsection{Explanatory Variables}

Sex and age were included as explanatory variables in our analyses. Sex was used as registered in GIANTT and defined as man or woman. Age was calculated on the index date and categorized in 11 age groups: $<40$ years, $40-44$ years, $45-49$ years, $50-54$ years, $55-59$ years, $60-64$ years, $65-69$ years, $70-74$ years, $75-79$ years, $80-84$ years, and $\geq 85$ years.

\subsection{Confounders}

We considered including body mass index (BMI), glycated hemoglobin A1c (HbA1c), and smoking status (smoker vs. non-smoker) as possible confounders. BMI and $\mathrm{HbA} 1 \mathrm{c}$ had less than $20 \%$ of missing values, which were imputed using multiple imputation by chained equations (MICE; Table S1). Smoking status was missing for more than $60 \%$ of patients and was therefore not included in our analyses.

\subsection{Analyses}

Patient characteristics per treatment group, sex, and age group were analyzed descriptively. More information about the time periods and definitions used for the patient characteristics can be found in Table S1.

We conducted linear regression analyses to assess differences in lipid levels between men and women across different age groups, including an interaction term between sex and age groups. BMI (continuous) was included as a possible confounder for all outcomes, since BMI differed between sex and age groups and it has been associated with the lipid profile. $\mathrm{HbA} 1 \mathrm{c}$ (continuous) was included as a possible confounder in the analysis of TG due to its relationship with TG levels [31]. Adjusted mean lipid levels with their $95 \%$ confidence intervals were estimated for all sex and age groups. The analyses were conducted separately for patients treated and not treated with a statin. Statin treatment was defined as the prescription of a statin in at least two out of three months before the index date. All statins prescribed and available in the study period were included, i.e., simvastatin, pravastatin, fluvastatin, atorvastatin, and rosuvastatin.

Sensitivity analyses were conducted for the primary outcome among those treated with a statin in which we additionally adjusted for moderate-intensity treatment (i.e., simvastatin, pravastatin, fluvastatin, atorvastatin $<40 \mathrm{mg}$, and rosuvastatin $<20 \mathrm{mg}$ ) versus high-intensity treatment (i.e., atorvastatin $\geq 40 \mathrm{mg}$ and rosuvastatin $\geq 20 \mathrm{mg}$ ) [18] with a statin (binary variable).

All analyses were conducted in Stata version 14 (Stata Corp., College Station, TX, USA), and two-sided $p$-values $<0.05$ were considered statistically significant.

\section{Results}

There were 26,849 patients included in this study (Figure 1), of which 13,733 (51\%) were women, and $14,894(55 \%)$ were treated with a statin. The proportion of patients treated with statins was higher among men than among women (58\% vs. $53 \%$ ). Among both non-treated and treated patients, women were older, had a longer diabetes duration, higher $\mathrm{BMI}$, more often had an estimated glomerular filtration rate (eGFR) $\leq 60 \mathrm{~mL} / \mathrm{min} / 1.73 \mathrm{~m}^{2}$, were more often treated with $\geq 5$ chronic medications, and were less often smokers than men (Table 1). Treatment with any glucose-lowering medication was similar for men and women. A similar proportion of men and women not treated with statins had a history of CVD, whereas for those treated with statins, men were more likely than women to 
have a history of CVD. Men were also more often treated with a high-intensity statin than women. In the highest age groups, women appeared to have a longer diabetes duration (Table S2). In both sexes, BMI was lower with higher age, whereas blood pressure, eGFR, and albuminuria were more unfavorable with higher age. Polypharmacy was most common in elderly women (Table S2). The percentage of patients with statin treatment was highest in the age groups between 55 and 79 years, and lowest in, particularly, the younger as well as the oldest women (Table S2).

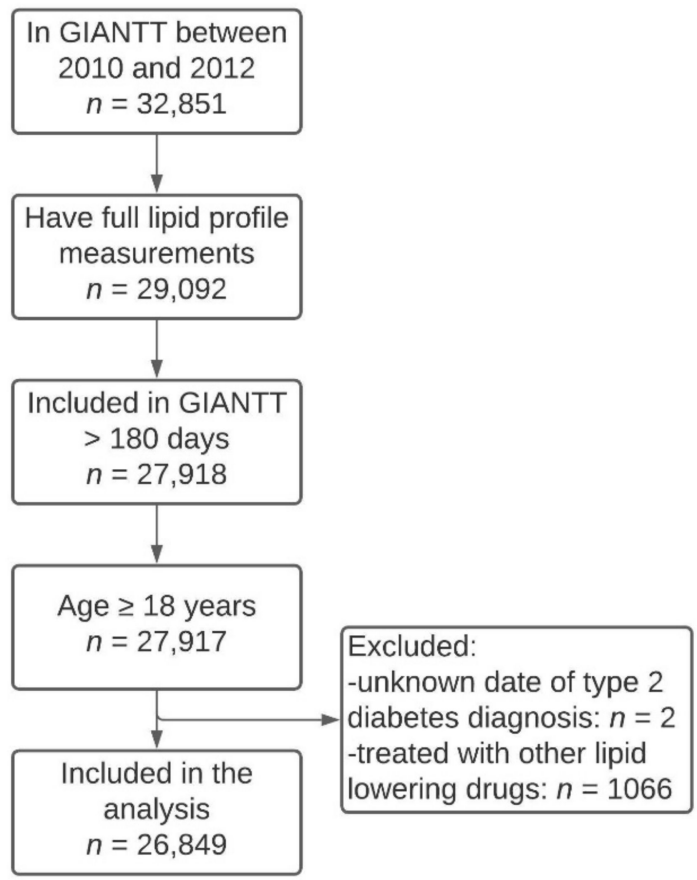

Figure 1. Flow chart with applied inclusion and exclusion criteria.

\subsection{Low-Density Lipoprotein Cholesterol, High-Density Lipoprotein Cholesterol, and Triglycerides}

In patients not treated with a statin, the mean BMI-adjusted LDL-c levels were above $3 \mathrm{mmol} / \mathrm{L}$ in all age groups except in men aged $\geq 85$ years (Figure 2A, left panel). Women had significantly lower LDL-c levels than men up to the age of 45 years and significantly higher LDL-c levels after the age of 50 years (Figure 2A left panel; Table S3A).

In patients treated with a statin, the mean BMI-adjusted LDL-c levels were below $2.5 \mathrm{mmol} / \mathrm{L}$ in all age groups (Figure 2A, right panel). There were no significant differences in LDL-c levels between men and women up to the age of 55 years. Between the age 55 and 84 years, we observed significantly higher LDL-c levels in women than in men (Figure 2A right panel; Table S3B).

Women had significantly higher BMI-adjusted HDL-c levels than men across all age groups, independent of statin treatment (Figure 2B, Table S3).

Men had significantly higher BMI- and HbA1c-adjusted TG levels than women up to the age of 55 and 60 years when not treated and treated with a statin, respectively, and similar levels thereafter (Figure 2C, Table S3).

The sensitivity analyses in which we additionally adjusted for the statin intensity showed similar results for LDL-c (Figure S1A), HDL-c (Figure S1B), and TGs (Figure S1C). 
Table 1. Demographics of included patients.

\begin{tabular}{|c|c|c|c|c|}
\hline & \multicolumn{2}{|c|}{ Not Treated with a Statin } & \multicolumn{2}{|c|}{ Treated with a Statin } \\
\hline & Men & Women & Men & Women \\
\hline Number (\%) & $5549(21)$ & $6406(24)$ & $7567(28)$ & $7327(27)$ \\
\hline Age in years; mean $\pm S D$ & $64 \pm 12$ & $68 \pm 14$ & $65 \pm 11$ & $68 \pm 11$ \\
\hline Diabetes duration; median (Q1-Q3) & $2.5(0.3-6.3)$ & $3.0(0.5-7.5)$ & $4.6(1.6-8.3)$ & $5.2(1.9-9.5)$ \\
\hline $\mathrm{HbA} 1 \mathrm{c}$ in $\%(\mathrm{mmol} / \mathrm{mol})$; median $(\mathrm{Q} 1-\mathrm{Q} 3)^{+}$ & $6.7(50)(6.3-7.5)$ & $6.7(50)(6.3-7.3)$ & $6.8(51)(6.4-7.4)$ & $6.8(51)(6.4-7.3)$ \\
\hline $\mathrm{BMI}$ in $\mathrm{kg} / \mathrm{m}^{2} ;$ mean $\pm \mathrm{SD}^{+}$ & $29.4 \pm 4.9$ & $30.8 \pm 6.1$ & $29.8 \pm 4.8$ & $30.9 \pm 5.8$ \\
\hline $\mathrm{SBP}$ in $\mathrm{mmHg}$; mean $\pm \mathrm{SD}^{+}$ & $142 \pm 19$ & $143 \pm 19$ & $141 \pm 18$ & $142 \pm 19$ \\
\hline $\mathrm{eGFR} \leq 60 \mathrm{~mL} / \mathrm{min} / 1.73 \mathrm{~m}^{2} ; n(\%)^{\dagger}$ & $487(10)$ & $1049(18)$ & $802(12)$ & $1232(18)$ \\
\hline Albuminuria; $n(\%)^{+}$ & $82(4)$ & $64(3)$ & $146(4)$ & $118(4)$ \\
\hline Polypharmacy; $n(\%)$ & $1361(25)$ & $2335(36)$ & $4420(58)$ & $4780(65)$ \\
\hline Glucose-lowering treatment; $n(\%)$ & $3145(57)$ & $3631(57)$ & $5965(79)$ & $5769(79)$ \\
\hline Smoking; $n(\%)^{+}$ & $505(25)$ & $461(20)$ & $837(27)$ & $630(21)$ \\
\hline History of CVD, $n(\%) \times$ & $1014(18)$ & $1143(18)$ & $2681(35)$ & $2007(27)$ \\
\hline LDL-c in mmol/L; mean $\pm \mathrm{SD}$ & $3.2 \pm 0.9$ & $3.4 \pm 1.0$ & $2.2 \pm 0.7$ & $2.3 \pm 0.8$ \\
\hline $\mathrm{HDL}-\mathrm{c}$ in $\mathrm{mmol} / \mathrm{L}$; mean $\pm \mathrm{SD}$ & $1.2 \pm 0.3$ & $1.4 \pm 0.4$ & $1.2 \pm 0.3$ & $1.4 \pm 0.4$ \\
\hline Triglycerides in mmol/L; mean $\pm \mathrm{SD}$ & $1.9 \pm 1.4$ & $1.8 \pm 1.0$ & $1.8 \pm 1.2$ & $1.7 \pm 0.9$ \\
\hline $\mathrm{TC}$ in $\mathrm{mmol} / \mathrm{L}$; mean $\pm \mathrm{SD}$ & $5.1 \pm 1.1$ & $5.4 \pm 1.1$ & $4.0 \pm 0.9$ & $4.3 \pm 0.9$ \\
\hline Non-HDL-c in mmol/L; mean \pm SD & $3.9 \pm 1.1$ & $4.0 \pm 1.1$ & $2.9 \pm 0.9$ & $3.0 \pm 0.9$ \\
\hline Total/HDL-c ratio; mean \pm SD & $4.6 \pm 1.5$ & $4.2 \pm 1.4$ & $3.7 \pm 1.1$ & $3.3 \pm 1.0$ \\
\hline High intensity statin; $n(\%) \ddagger$ & $\mathrm{n} / \mathrm{a}$ & $\mathrm{n} / \mathrm{a}$ & $693(9)$ & $499(7)$ \\
\hline
\end{tabular}

${ }^{\dagger}$ Glycated hemoglobin A1c (HbA1c): 627 (2.3\%) missing values; Body mass index (BMI): 4403 (16.4\%) missing values; Systolic blood pressure (SBP): 9852 (36.7\%) missing values; Estimated glomerular filtration rate (eGFR): 2480 (9.2\%) missing values; Albuminuria: 15,473 (57.6\%) missing values; Smoking: 16,447 (61.3\%) missing values. DDP-4: dipeptidylpeptidase-4; CVD: cardiovascular disease; LDL: low-density lipoprotein; HDL: high-density lipoprotein; TC: total cholesterol. ${ }^{\times}$Includes any record of the presence of angina pectoris, acute myocardial infarction, transient ischemic attack, stroke, atherosclerosis, other ischemic heart diseases and peripheral arterial diseases, abdominal aortic aneurysm, percutaneous transluminal (coronary) angioplasty, and peripheral or coronary bypass before the index date.

$\ddagger$ Daily dose of atorvastatin $\geq 40 \mathrm{mg}$ and rosuvastatin $\geq 20 \mathrm{mg}$; data on dose missing for eight patients.

\subsection{Total Cholesterol and Non-High-Density Lipoprotein Cholesterol}

In patients not treated with a statin, TC and non-HDL-c levels showed similar sex and age patterns as seen for the LDL-c levels, with lower levels in women than in men younger than 45 and 50 years, respectively, and higher levels in women than in men after the age of 50 and 55 years, respectively (Figure S2A,B and Table S3).

For those treated with a statin, women and men had similar TC levels up to the age of 50 years, but women had higher levels than men thereafter (Figure S2A, Table S3). NonHDL levels were higher in men than in women aged 45-49 years and higher in women than in men older than 60 years, but they were similar in both sexes in other age groups (Figure S2B, Table S3). 

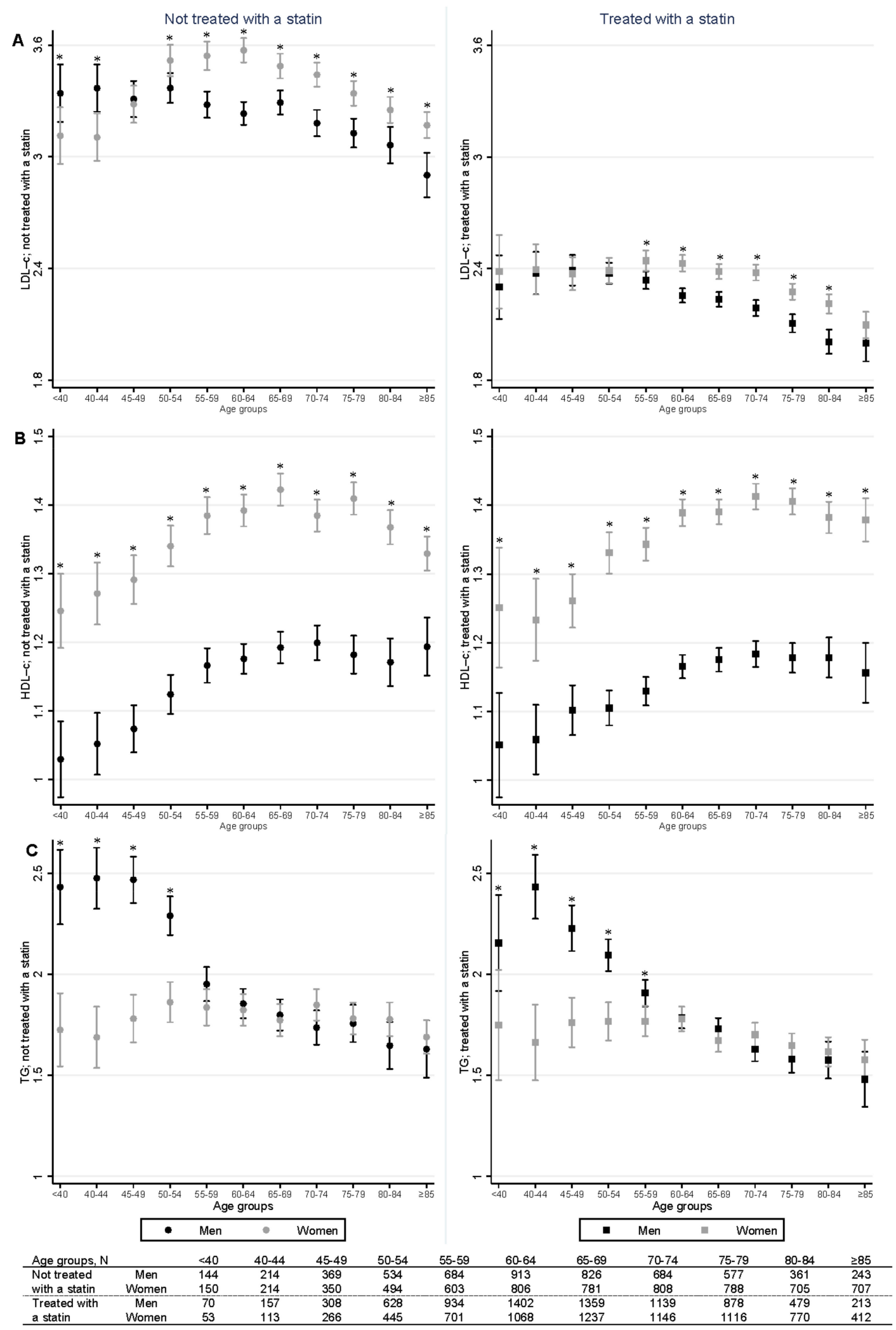

Figure 2. Mean lipid levels with 95\% CIs for men and women per age group not treated (left) and treated with a statin (right). (A) Low-density lipoprotein cholesterol (LDL-c), (B) high-density lipoprotein cholesterol (HDL-c), and (C) triglyceride (TG) levels. Cholesterol measurements are in $\mathrm{mmol} / \mathrm{L}$. All values were adjusted for body mass index; TG values were additionally adjusted for glycated hemoglobin A1c. ${ }^{*} p<0.05$ between men and women. 


\section{Discussion}

This study showed that differences in lipid levels between women and men with T2D change substantially across the life span. For patients not treated with a statin, women had lower LDL-c levels than men before the age of 45 years and higher LDL-c levels after the age of 50 years. Statin treatment lowered LDL-c levels in both women and men, but women still had higher LDL-c levels than men after the age of 55 years. HDL-c levels were consistently higher in women than in men in all age groups, regardless of statin treatment. TG levels were higher in men than in women before the age of 60 years, regardless of statin treatment.

\subsection{Comparison with Existing Literature}

Sex differences in LDL-c levels in T2D have previously been reported, with women having higher levels than men $[16,22,26]$. These studies did not allow for conclusions regarding age-dependent effects. Several other studies incorporated age in the analysis but divided the patients in only two age groups, using a cut-off of 60 or 65 years [21,24], or used broad age groups [32]. In addition, these studies were limited by not stratifying the patients by statin use. Our study adds to this knowledge, showing that higher LDL-c levels in women than men occur only after the age of 50 and 55 years among T2D patients without or with statin treatment, respectively, which is around the mean age of menopause in the Netherlands [33]. In line with our results, a previous study among 8775 T2D patients not stratifying for statin treatment found higher LDL-c levels in women than in men only after the age of 45 years [25]. In contrast, a small study of 110 patients with T2D and 74 controls did not observe sex differences in LDL-c levels between diabetic preand postmenopausal women [17]. This study, however, was limited by including only eight premenopausal diabetic women and did not stratify or adjust for statin treatment. Our findings show that unfavorable lipid profiles in women with T2D are particularly a postmenopausal phenomenon [10,11,34,35]. Although sex differences in LDL-c levels have been acknowledged in the general population $[2,7,11,36]$, this is the first study presenting a detailed analysis of the differences across age groups in a large cohort of patients with T2D. We observed similar differences with respect to non-HDL-c, a proposed atherogenic lipid risk marker for patients with T2D and non-diabetic individuals [37-39]. The unfavorable lipid profile in women is not fully mitigated by statin treatment, since even with statin treatment, LDL-c and non-HDL-c levels in women remained higher than in men after the age of 55 years. This could be due to less intensive treatment in women [40,41], but the relationship between sex differences in treatment intensity and menopause has not been explored. We conducted a sensitivity analysis adjusting for statin intensity and observed a similar pattern of higher LDL-c levels among women after menopause. Alternative explanations for these differences need further study by considering both possible sex(biology and physiology) as well as gender- (behavior and psychology) related differences. To reach similar LDL-c levels, women with T2D above the age of 50 may have to be treated more aggressively than men. Although, on average, T2D patients treated with a statin achieved a level of LDL-c $<2.4 \mathrm{mmol} / \mathrm{L}$, around half of the women between 55 and 75 years of age treated with statins showed higher LDL-c levels. Particularly, in patients with T2D and additional risk factors, lower LDL-c levels might be more appropriate $[18,19,42]$. Our study illustrates that in women with T2D before menopause, there might still be a protective biological effect, which was previously assumed to be abrogated by the presence of T2D [17].

Previous studies looking at sex-related differences in HDL-c levels in patients with T2D reported higher HDL-c levels in women than in men [22,24,32], unrelated to patients' age [21,24]. In line with these observations, we observed higher HDL-c levels in women in all age groups. Statin treatment did not affect HDL-c levels in our study, which is consistent with the mode of action of statins and previous research [42] and did not affect sex differences in HDL-c levels. 
The high TG levels in younger and middle-aged men compared to women and older men have been observed previously in both the general population $[7,43]$ and a population with T2D [25]. Our findings add the observation that these high TG levels in younger men are not much lowered when patients are treated with statins. This observation could be explained by a higher BMI and more visceral fat in men [44,45] but, since our analyses were adjusted for BMI, this is an unlikely explanation. The higher TG levels in young men with T2D deserve further study, particularly since the combination of increased TG levels and low HDL-c levels has been associated with a $44 \%$ increase in the occurrence of major cardiovascular events also in patients with T2D [46].

\subsection{Strengths and Limitations}

A strength of our study is the use of real-world data from a large cohort of patients with T2D, treated in primary care. To the best of our knowledge, it is the first study to investigate sex-related differences in lipid levels in these patients at different ages, with and without statin treatment. Our study also has some limitations. First, this is a cross-sectional design, so there can be potential historical demographic, nutritional, and healthcare system differences between older and younger patients included in our study. Also, mostly Caucasian people were included, which limits the application of the results to other races. Further, smoking could not be included as a confounder in the analyses due to the high proportion of missing data. Also, information on alcohol consumption and other lifestyle behaviors was not available in our database. Since such behaviors can differ between sexes and with age, this may have influenced the results due to their effects on lipid levels. In addition, we could not adjust for potential differences between men and women regarding adherence to statins. Finally, there was no information about the start of menopause in the GIANTT database, but the mean age of menopause in the Netherlands has been estimated to be $50.4 \pm 4.1$ years [33].

\section{Conclusions}

Among younger patients with T2D, women seemed to have a more favorable lipid profile than men, since they had lower LDL-c and TG levels and higher HDL-c levels. Younger men with T2D had particularly high TG levels. Among patients with T2D older than 50 years, women had higher LDL-c levels than men. Statin treatment partly lowered the observed sex differences, but more than half of the patients with T2D were not treated with statins. When managing cardiovascular risk in patients with T2D, more attention is needed for the menopausal status of women and for TG levels in younger men.

Supplementary Materials: The following are available online at https:/ / www.mdpi.com/article/ 10.3390/jcm10081775/s1, Table S1: Extraction time periods and definitions of variables used in the analyses; Table S2: Patient demographics in those not treated and treated with a statin per sex and age group; Table S3: Sex differences in lipid levels across age groups adjusted for BMI in those (A) not treated and (B) treated with a statin. Cholesterol measurements are in mmol/L; Figure S1: Mean lipid levels with $95 \%$ CIs for men and women per age group treated by a statin of (A) low-density lipoprotein cholesterol (LDL-c), (B) high-density lipoprotein cholesterol (HDL-c) and (C) triglycerides (TG). Cholesterol measurements are in $\mathrm{mmol} / \mathrm{L}$. Values are adjusted for body mass index and statin dose (moderate versus high; dose was not available for 8 patients); TG values are additionally adjusted for glycated hemoglobin A1c. ${ }^{*} p<0.05$ between men and women; Figure S2: Mean lipid levels with $95 \%$ CIs for men and women per age group in those not treated (left) and treated with a statin (right) of (A) total cholesterol (TC) and (B) non-HDL cholesterol. Cholesterol measurements are in mmol/L. All values are adjusted for body mass index (BMI); TG values are additionally adjusted for glycated hemoglobin A1c. ${ }^{*} p<0.05$ between men and women.

Author Contributions: Conceptualization, M.A., S.T.d.V., J.R.v.L., R.P.F.D., P.D., and K.H.; Data curation, M.A., S.T.d.V., and P.D.; Formal analysis, M.A., S.T.d.V., and P.V.; Funding acquisition, P.D.; Investigation, M.A. and S.T.d.V.; Methodology, M.A., S.T.d.V., P.V., and P.D.; Project administration, M.A. and P.D.; Software, M.A.; Supervision, S.T.d.V., P.D., and K.H.; Validation, S.T.d.V. and P.D.; 
Visualization, M.A.; Writing-original draft, M.A.; Writing-review \& editing, S.T.d.V., P.V., R.P.F.D., J.R.v.L., P.D., and K.H. All authors have read and agreed to the published version of the manuscript.

Funding: This project has received funding from the European Union's Horizon 2020 research and innovation program under the Marie Skłodowska-Curie grant agreement No 754425.

Institutional Review Board Statement: We obtained an exemption letter from the University Medical Center Groningen Medical Ethics Review Board (reference number M20.257509).

Informed Consent Statement: Patient consent was waived since for scientific research with anonymous data, an opt-out policy is offered in the Netherlands. Only data from patients who did not opt-out for the use of their medical data for scientific research were used.

Data Availability Statement: The datasets used and/or analyzed during the current study are available from the corresponding author on reasonable request.

Conflicts of Interest: The authors declare no conflict of interest.

\section{References}

1. WHO. The Top 10 Causes of Death. 2018. Available online: https://www.who.int/news-room/fact-sheets/detail/the-top-10 -causes-of-death (accessed on 10 March 2021).

2. Pilote, L.; Dasgupta, K.; Guru, V.; Humphries, K.H.; McGrath, J.; Norris, C.; Rabi, D.; Tremblay, J.; Alamian, A.; Barnett, T. A comprehensive view of sex-specific issues related to cardiovascular disease. CMAJ 2007, 176, S1-S44. [CrossRef] [PubMed]

3. Maas, A.H.; Appelman, Y.E. Gender differences in coronary heart disease. Neth. Heart J. 2010, 18, 598-602. [CrossRef] [PubMed]

4. Appelman, Y.; van Rijn, B.B.; Ten Haaf, M.E.; Boersma, E.; Peters, S.A. Sex differences in cardiovascular risk factors and disease prevention. Atherosclerosis 2015, 241, 211-218. [CrossRef] [PubMed]

5. Huebschmann, A.G.; Huxley, R.R.; Kohrt, W.M.; Zeitler, P.; Regensteiner, J.G.; Reusch, J.E.B. Sex differences in the burden of type 2 diabetes and cardiovascular risk across the life course. Diabetologia 2019,62, 1761-1772. [CrossRef]

6. Peters, S.A.E.; Huxley, R.R.; Sattar, N.; Woodward, M. Sex differences in the excess risk of cardiovascular diseases associated with type 2 diabetes: Potential explanations and clinical implications. Curr. Cardiovasc. Risk Rep. 2015, 9, 36. [CrossRef]

7. Balder, J.W.; de Vries, J.K.; Nolte, I.M.; Lansberg, P.J.; Kuivenhoven, J.A.; Kamphuisen, P.W. Lipid and lipoprotein reference values from 133,450 Dutch Lifelines participants: Age- and gender-specific baseline lipid values and percentiles. J. Clin. Lipidol. 2017, 11, 1055-1064. [CrossRef]

8. Matthews, K.A.; Meilahn, E.; Kuller, L.H.; Kelsey, S.F.; Caggiula, A.W.; Wing, R.R. Menopause and risk factors for coronary heart disease. N. Engl. J. Med. 1989, 321, 641-646. [CrossRef] [PubMed]

9. Akahoshi, M.; Soda, M.; Nakashima, E.; Shimaoka, K.; Seto, S.; Yano, K. Effects of menopause on trends of serum cholesterol, blood pressure, and body mass index. Circulation 1996, 94, 61-66. [CrossRef]

10. Berg, G.; Mesch, V.; Boero, L.; Sayegh, F.; Prada, M.; Royer, M.; Muzzio, M.L.; Schreier, L.; Siseles, N.; Benencia, H. Lipid and lipoprotein profile in menopausal transition. Effects of hormones, age and fat distribution. Horm. Metab. Res. 2004, 36, 215-220.

11. Li, Z.; McNamara, J.R.; Fruchart, J.C.; Luc, G.; Bard, J.M.; Ordovas, J.M.; Wilson, P.W.; Schaefer, E.J. Effects of gender and menopausal status on plasma lipoprotein subspecies and particle sizes. J. Lipid Res. 1996, 37, 1886-1896. [CrossRef]

12. Kannel, W.B.; McGee, D.L. Diabetes and glucose tolerance as risk factors for cardiovascular disease: The Framingham study. Diabetes Care 1979, 2, 120-126. [CrossRef]

13. Sarwar, N.; Gao, P.; Seshasai, S.R.; Gobin, R.; Kaptoge, S.; Di Angelantonio, E. Diabetes mellitus, fasting blood glucose concentration, and risk of vascular disease: A collaborative meta-analysis of 102 prospective studies. Lancet 2010, 375, $2215-2222$.

14. Peters, S.A.E.; Huxley, R.R.; Woodward, M. Diabetes as risk factor for incident coronary heart disease in women compared with men: A systematic review and meta-analysis of 64 cohorts including 858,507 individuals and 28,203 coronary events. Diabetologia 2014, 57, 1542-1551. [CrossRef]

15. Peters, S.A.E.; Huxley, R.R.; Woodward, M. Diabetes as a risk factor for stroke in women compared with men: A systematic review and meta-analysis of 64 cohorts, including 775,385 individuals and 12,539 strokes. Lancet 2014, 383, 1973-1980. [CrossRef]

16. De Jong, M.; Oskam, M.J.; Sep, S.J.S.; Ozcan, B.; Rutters, F.; Sijbrands, E.J.G.; Elders, P.J.M.; Siegelaar, S.E.; DeVries, J.H.; Tack, C.J.; et al. Sex differences in cardiometabolic risk factors, pharmacological treatment and risk factor control in type 2 diabetes: Findings from the Dutch Diabetes Pearl cohort. BMJ Open Diabetes Res. Care 2020, 8, e001365. [CrossRef] [PubMed]

17. Mascarenhas-Melo, F.; Marado, D.; Palavra, F.; Sereno, J.; Coelho, Á.; Pinto, R.; Teixeira-Lemos, E.; Teixeira, F.; Reis, F. Diabetes abrogates sex differences and aggravates cardiometabolic risk in postmenopausal women. Cardiovasc. Diabetol. 2013, 12, 1-14. [CrossRef]

18. ADA. 10. Cardiovascular Disease and Risk Management: Standards of Medical Care in Diabetes-2021. Diabetes Care 2021, 44 (Suppl. 1), S125-S150. [CrossRef]

19. NHG. Praktische Handleiding bij de NHG-Standaard CVRM (Practical Manual for the NHG-Standard CVRM); Nederlands Huisartsen Genootschap (NHG) (Dutch College of General Practitioners): Utrecht, The Netherlands, 2019. 
20. Kearney, P.M.; Blackwell, L.; Collins, R. Efficacy of cholesterol-lowering therapy in 18,686 people with diabetes in 14 randomised trials of statins: A meta-analysis. Lancet 2008, 371, 117-125. [PubMed]

21. De Jong, M.; Vos, R.C.; de Ritter, R.; van der Kallen, C.J.; Sep, S.J.; Woodward, M.; Stehouwer, C.D.A.; Bots, M.L.; Peters, S.A.E. Sex differences in cardiovascular risk management for people with diabetes in primary care: A cross-sectional study. BJGP Open 2019, 3, 1-11. [CrossRef]

22. Wexler, D.J.; Grant, R.W.; Meigs, J.B.; Nathan, D.M.; Cagliero, E. Sex disparities in treatment of cardiac risk factors in patients with type 2 diabetes. Diabetes Care 2005, 28, 514-520. [CrossRef] [PubMed]

23. De Vries, F.M.; Voorham, J.; Hak, E.; Denig, P. Adherence to standard-dose or low-dose statin treatment and low-density lipoprotein cholesterol response in type 2 diabetes patients. Curr. Med. Res. Opin. 2015, 31, 2197-2206. [CrossRef] [PubMed]

24. Franzini, L.; Ardigo, D.; Cavalot, F.; Miccoli, R.; Rivellese, A.A.; Trovati, M.; Zavaronia, I.; Vaccarod, O. Women show worse control of type 2 diabetes and cardiovascular disease risk factors than men: Results from the MIND.IT Study Group of the Italian Society of Diabetology. Nutr. Metab. Cardiovasc. Dis. 2013, 23, 235-241. [CrossRef] [PubMed]

25. Sekerija, M.; Poljicanin, T.; Erjavec, K.; Liberati-Cizmek, A.M.; Prasek, M.; Metelko, Z. Gender differences in the control of cardiovascular risk factors in patients with type 2 diabetes -a cross-sectional study. Intern. Med. 2012, 51, 161-166. [CrossRef] [PubMed]

26. Strom Williams, J.L.; Lynch, C.P.; Winchester, R.; Thomas, L.; Keith, B.; Egede, L.E. Gender differences in composite control of cardiovascular risk factors among patients with type 2 diabetes. Diabetes Technol. Ther. 2014, 16, 421-427. [CrossRef] [PubMed]

27. Tamargo, J.; Rosano, G.; Walther, T.; Duarte, J.; Niessner, A.; Kaski, J.C.; Ceconi, C.; Drexel, K.; Kjeldsen, K.; Savarese, G.; et al. Gender differences in the effects of cardiovascular drugs. Eur. Heart J. Cardiovasc. Pharmacother. 2017, 3, 163-182. [CrossRef] [PubMed]

28. De Vries, S.T.; Voorham, J.; Haaijer-Ruskamp, F.M.; Denig, P. Potential overtreatment and undertreatment of diabetes in different patient age groups in primary care after the introduction of performance measures. Diabetes Care 2014, 37, 1312-1320. [CrossRef]

29. Voorham, J.; Haaijer-Ruskamp, F.M.; van der Meer, K.; de Zeeuw, D.; Wolffenbuttel, B.H.; Hoogenberg, K.; Denig, P. Identifying targets to improve treatment in type 2 diabetes; the Groningen Initiative to aNalyse Type 2 diabetes Treatment (GIANTT) observational study. Pharmacoepidemiol. Drug Saf. 2010, 19, 1078-1086. [CrossRef]

30. Vos, R.C.; den Ouden, H.; Daamen, L.A.; Bilo, H.J.G.; Denig, P.; Rutten, G. Population-based screen-detected type 2 diabetes mellitus is associated with less need for insulin therapy after 10 years. BMJ Open Diabetes Res. Care 2020, 8, e000949. [CrossRef] [PubMed]

31. Alzahrani, S.H.; Baig, M.; Aashi, M.M.; Al-Shaibi, F.K.; Alqarni, D.A.; Bakhamees, W.H. Association between glycated hemoglobin (HbA1c) and the lipid profile in patients with type 2 diabetes mellitus at a tertiary care hospital: A retrospective study. Diabetes Metab. Syndr. Obes. 2019, 12, 1639-1644. [CrossRef] [PubMed]

32. Russo, G.; Pintaudi, B.; Giorda, C.; Lucisano, G.; Nicolucci, A.; Cristofaro, M.R.; Suraci, C.; Mulas, M.F.; Napoli, A.; Rossi, M.C.; et al. Age- and gender-related differences in LDL-cholesterol management in outpatients with type 2 diabetes mellitus. Int. J. Endocrinol. 2015, 2015, 1-8. [CrossRef]

33. Van Disseldorp, J.; Faddy, M.J.; Themmen, A.P.; de Jong, F.H.; Peeters, P.H.; van der Schouw, Y.T.; Broekmans, F.J.M. Relationship of serum antimüllerian hormone concentration to age at menopause. J. Clin. Endocrinol. Metab. 2008, 93, 2129-2134. [CrossRef]

34. Matthews, K.A.; Crawford, S.L.; Chae, C.U.; Everson-Rose, S.A.; Sowers, M.F.; Sternfeld, B.; Sutton-Tyrrell, K. Are changes in cardiovascular disease risk factors in midlife women due to chronological aging or to the menopausal transition? J. Am. Coll. Cardiol. 2009, 54, 2366-2373. [CrossRef]

35. Fonseca, M.I.H.; da Silva, I.T.; Ferreira, S.R.G. Impact of menopause and diabetes on atherogenic lipid profile: Is it worth to analyse lipoprotein subfractions to assess cardiovascular risk in women? Diabetol. Metab. Syndr. 2017, 9, 1-13. [CrossRef]

36. Pavanello, C.; Mombelli, G. Considering gender in prescribing statins: What do physicians need to know? Clin. Lipidol. 2015, 10, 499-512. [CrossRef]

37. Brunner, F.J.; Waldeyer, C.; Ojeda, F.; Salomaa, V.; Kee, F.; Sans, S.; Thorand, P.B.; Giampaoli, S.; Brambilla, P.; Tunstall-Pedoe, P.H.; et al. Application of non-HDL cholesterol for population-based cardiovascular risk stratification: Results from the Multinational Cardiovascular Risk Consortium. Lancet 2019, 394, 2173-2183. [CrossRef]

38. Cao, Y.; Yan, L.; Guo, N.; Yu, N.; Wang, Y.; Cao, X.; Yang, S.; Lv, F. Non-high-density lipoprotein cholesterol and risk of cardiovascular disease in the general population and patients with type 2 diabetes: A systematic review and meta-analysis. Diabetes Res. Clin. Pract. 2019, 147, 1-8. [CrossRef] [PubMed]

39. Lu, W.; Resnick, H.E.; Jablonski, K.A.; Jones, K.L.; Jain, A.K.; Howard, W.J.; Robbins, D.C.; Howard, B.V. Non-HDL cholesterol as a predictor of cardiovascular disease in type 2 diabetes: The strong heart study. Diabetes Care 2003, 26, 16-23. [CrossRef] [PubMed]

40. Gouni-Berthold, I.; Berthold, H.K.; Mantzoros, C.S.; Bohm, M.; Krone, W. Sex disparities in the treatment and control of cardiovascular risk factors in type 2 diabetes. Diabetes Care 2008, 31, 1389-1391. [CrossRef] [PubMed]

41. Wright, A.K.; Kontopantelis, E.; Emsley, R.; Buchan, I.; Mamas, M.A.; Sattar, N.; Ashcroft, D.M.; Rutter, M.K. Cardiovascular risk and risk factor management in type 2 diabetes mellitus. Circulation 2019, 139, 2742-2753. [CrossRef]

42. Mach, F.; Baigent, C.; Catapano, A.L.; Koskinas, K.C.; Casula, M.; Badimon, L.; John Capman, M.; De Backer, G.G.; Delgado, V.; Ference, B.A.; et al. 2019 ESC/EAS Guidelines for the management of dyslipidaemias: Lipid modification to reduce cardiovascular risk. Eur. Heart J. 2020, 41, 111-188. [CrossRef] 
43. Cullen, P.; Schulte, H.; Assmann, G. The Münster Heart Study (PROCAM): Total mortality in middle-aged men is increased at low total and LDL cholesterol concentrations in smokers but not in nonsmokers. Circulation 1997, 96, 2128-2136. [CrossRef] [PubMed]

44. Kautzky-Willer, A.; Harreiter, J.; Pacini, G. Sex and gender differences in risk, pathophysiology and complications of type 2 diabetes mellitus. Endocr. Rev. 2016, 37, 278-316. [CrossRef] [PubMed]

45. Couillard, C.; Bergeron, N.; Prud'homme, D.; Bergeron, J.; Tremblay, A.; Bouchard, C.; Mauriège, P.; Després, J.-P. Gender difference in postprandial lipemia: Importance of visceral adipose tissue accumulation. Arterioscler. Thromb. Vasc. Biol. 1999, 19, 2448-2455. [CrossRef] [PubMed]

46. Castaner, O.; Pinto, X.; Subirana, I.; Amor, A.J.; Ros, E.; Hernaez, A.; Martínez-González, M.Á.; Corella, D.; Salas-Salvadó, J.; Estruch, R.; et al. Remnant cholesterol, not LDL cholesterol, is associated with incident cardiovascular disease. J. Am. Coll. Cardiol. 2020, 76, 2712-2724. [CrossRef] [PubMed] 